\title{
The productivity impact of information technology in the healthcare industry: an empirical study using a regression spline-based approach
}

\author{
Myung $\mathrm{Ko}^{\mathrm{a}, *}$, Kweku-Muata Osei-Bryson ${ }^{\mathrm{b}}$ \\ ${ }^{a}$ Department of Information Systems, College of Business, The University of Texas at San Antonio, San Antonio, TX 78249, USA \\ ${ }^{\mathrm{b}}$ Department of Information Systems and The Information Systems Research Institute, School of Business, Virginia Commonwealth University, \\ Richmond, VA 23284, USA
}

Received 14 October 2002; revised 10 May 2003; accepted 19 June 2003

\begin{abstract}
This paper explores the productivity impact of information technology (IT) in the healthcare industry using a regression spline (RS)-based approach. Application of the RS-based approach offered additional valuable insights that contribute to our understanding of the complex relationship between investments in IT and organizational productivity. For example, the results of this study suggest that investments in the IT Stock has a positive impact on productivity only under certain conditions, and that this impact of IT is not uniform but is conditioned both by the amount invested in the IT Stock and the investments in Non-IT Capital.

(C) 2003 Elsevier B.V. All rights reserved.
\end{abstract}

Keywords: Information technology investments; Productivity; Regression splines; Data mining; Multivariate adaptive regression splines

\section{Introduction}

Investments in information technology (IT) have grown continuously over the past 30 years [1]. Recently, IT became the largest item of capital expenditure in most organizations [2]. While organizations have invested in IT as a means to improve organizational performance, many previous IS researchers have failed to show any evidence of the IT impact on organizational productivity. This 'IT productivity paradox' has been a debated issue since the mid-1980s [3-7]. While recent firm level studies have claimed that the IT productivity paradox no longer exists [5, $8-10]$, Morgan Stanley reported that US companies wasted $\$ 130$ billion in the past 2 years on technology [11].

In this paper, we explore the productivity impact of IT investments in the healthcare industry utilizing a dataset that has been used in another study [12]. In this study, we take another look at this issue by applying a relatively new technique, multivariate adaptive regression splines (MARS) that, we believe, offers the opportunity for rich analysis.

\footnotetext{
* Corresponding author.

E-mail addresses: mko@utsa.edu (M. Ko), kweku.muata@isy.vcu.edu (K.M. Osei-Bryson).
}

\section{Overview on previous research}

Several studies have examined the productivity impact of IT investments, and their findings have been inconsistent. While Loveman [13] found no evidence of productivity increase from IT investments, some studies have mixed results. Weill [14] found that transactional IT investments had a positive impact on firm performance but strategic IT or informational IT did not. Prasad and Harker [6] found that IT labor produced substantial high returns in productivity but IT capital did not. Lee and Menon [15] found that IT capital was associated with increased productivity but IT labor did not. On the other hand, some studies have found a positive relationship. Hitt and Brynjolfsson [5] found that IT spending has a positive impact on productivity and provided significant value for consumers. Shao and Lin [10] found that IT has a positive effect on technical efficiency in the production process whether IT investments are treated as a firm-specific factor or a production factor. Menon et al. [12] found that non-IT labor showed the highest positive impact on productivity. In their study, IT labor and non-IT labor contributed positively to productivity while IT capital contributed low average productivity. However, non-IT capital showed a negative 
Table 1

Summary of empirical firm level studies of the IT productivity

\begin{tabular}{lrl}
\hline Study & Sample size/period & Findings \\
\hline Ref. [14] & $33 / 1982-1987$ & Transactional IT: $\uparrow ;$ strategic or informational IT: $\leftrightarrow$ \\
Ref. [13] & $60 / 1978-1984$ & Productivity: $\leftrightarrow$ \\
Ref. [5] & $1109 / 1988-1992$ & Productivity and consumer value: $\uparrow$ \\
Ref. [6] & $47 / 1993-1995$ & IT labor and productivity: $\uparrow ;$ IT capital and productivity: $\leftrightarrow$ or: $\downarrow$ \\
Ref. [10] & $1115 / 1988-1992$ & IT and technical efficiency: $\uparrow ;$ thus, IT and productivity: $\uparrow$ \\
Ref. [15] & $1064 / 1976-1994$ & IT capital and productivity: $\uparrow ;$ IT labor and productivity: $\downarrow$ \\
Ref. [12] & $1064 / 1976-1994$ & Between medical labor, IT labor, medical IT capital and productivity: $\uparrow ;$ \\
& & medical capital and productivity: $\downarrow$ \\
\hline
\end{tabular}

$\uparrow$ : Positive relationship (or increase productivity); $\leftrightarrow:$ no effect; $\downarrow:$ negative relationship (or decrease productivity).

impact on productivity in their study. Table 1 includes a summary of the previous IT productivity research.

\section{Description of the dataset}

We used a dataset that has also been previously used in another study on the impact of IT investments on productivity in the healthcare industry [12]. The source data were collected by the Washington State Department of Health (DOH), and include the departmental-level costs and charges for 83 accounts for each hospital in the Washington state for the period from 1976 to 1994. The dataset excludes any specialized hospitals such as psychiatric and substance abuse treatment centers. Overall, the dataset consists of $1130^{1}$ observations.

Each hospital accumulates its charges and costs based on the account number. Charges include the total dollars billed for patient services during the period, not considering any reimbursement. Costs include expenses such as salaries and wages, employee benefits, supplies, and rental/lease. Capital expenses were categorized as IT Capital, Medical IT Capital, and Non-IT Capital. IT Capital includes capital expenses incurred mainly for administrative purposes in the departmental accounts that are shown in Table 2. Medical IT Capital includes capital expenses incurred for the equipment used for diagnosing and therapeutics in the departmental accounts that are shown in Table 2. Non-IT Capital includes capital expenses incurred for the equipment used only for therapeutic purposes and also includes any capital expenses in remaining departmental accounts. Labor expenses were classified as two categories: IT Labor and Non-IT Labor. The salaries and employee benefits incurred in departments where their capital expenses were classified as IT Capital were categorized as IT Labor and those expenses incurred in remaining departments were classified as Non-IT Labor. From these variables, IT Stock, which represents IT investments, is constructed by combining IT Capital and a capitalized value of IT Labor expenses. Medical IT Capital is considered as part of IT investments

\footnotetext{
${ }^{1}$ The number of observations is larger than that in Ref. [12] because MARS handles missing values differently compared to regression model.
}

and IT Labor is treated as part of IT investments since IT Labor represents a type of expenditure that produces a capital asset which lasts 3 years on the average [5]. Thus, the data are categorized into three variables: IT Stock, Non-IT Capital, and Non-IT Labor. The output is the hospital performance measure, Adjusted Patient Days, which can be calculated as the sum of inpatient days and outpatient days. For detailed description of variables, the reader may refer to the study by Menon et al. [12].

\section{The production function}

The theory of production assumes that a firm uses various inputs to produce its outputs based on the rules specified by the firm's production function [16]. Many previous studies that have explored the relationship between IT investments and productivity have also used this theoretical base $[1,5,13,17]$. For this study, the target (i.e. dependent) variable, $Q$ is the hospital's Adjusted Patient Days (see Table 2) and the predictor (i.e. independent) variables are Non-IT Capital $(K)$, Non-IT Labor $(L)$, and IT Stock $(T)$, where IT Stock includes IT Capital, Medical IT Capital and IT Labor in a manner similar to its use in the study by Hitt and Brynjolfsson [5]. Since we assume that a hospital's Adjusted Patient Days $(Q)$ depends on the use of IT Stock $(T)$, Non-IT Capital $(K)$, and the Non-IT Labor $(L)$, then our production function has the following form:

$Q=f(K, L, T)$

Although the most widely known production function is the Cobb-Douglas function, the translog production function has also been used. While other studies have used it to explain the impact of IT investments on productivity, those studies have used regression analysis to identify statistically significant variables and interactions. In this study, our analysis is also based on translog production function because it enables us to explore interactions between our predictor (or independent) variables. However, unlike other studies, we use regression splines (RS) analysis to understand the complex relationship between IT investments and productivity in the healthcare industry. 
Table 2

Variable definitions (source: Ref. [12] and Menon's SAS program)

\begin{tabular}{|c|c|}
\hline Variable & Description (or departmental account) \\
\hline Adjusted Patient Days $(Q)$ & $\begin{array}{l}\text { Adjusted patient days (sum of inpatient days and outpatient days). Outpatient days are derived by dividing outpatient } \\
\text { revenue by inpatient revenue per day. Deflated by the output price (see below) }\end{array}$ \\
\hline IT Stock $(T)$ & Calculated as IT capital plus medical IT capital plus three times IT labor \\
\hline IT Capital $(T)$ & $\begin{array}{l}\text { Capital expenses incurred in data processing, communications, admitting, patient accounts, central services, purchasing, } \\
\text { accounting, medical records, personnel, medical library, medical staff, and utilization management. Deflated by price } \\
\text { deflator for fixed investment for IT from WEFA-1994 }\end{array}$ \\
\hline Medical IT Capital & $\begin{array}{l}\text { Capital expenses incurred in MRI, CT scanning services, surgical services, recovery room, anesthesiology, IV therapy } \\
\text { services, electrodiagnosis, radiology-diagnostic, radiology-therapeutic, emergency room, nuclear medicine, } \\
\text { electromyography, lithotripsy, organ acquisitions, outpatient chemical deposit. Deflated by price deflator for fixed } \\
\text { investment for IT from WEFA-1994 }\end{array}$ \\
\hline Non-IT Capital $(K)$ & $\begin{array}{l}\text { Capital expenses incurred in intensive/coronary care, semi-intensive care, acute care, physical rehabilitation, psychiatric, } \\
\text { nursery, laboratory, pharmacy, home care services and any remaining accounts. Deflated by price deflator for fixed } \\
\text { investment for non-IT from WEFA-1994 }\end{array}$ \\
\hline IT Labor & Salaries and employee benefits charged to IT capital accounts. Deflated by labor price (see below) \\
\hline Labor Price & Employment price index for health care services from Bureau of Labor Statistics (BLS) (1995) \\
\hline Output Price & Consumer price index for health care services from WEFA (1994) \\
\hline
\end{tabular}

The Translog function is a generalization of the CobbDouglas functional form, relaxing the constraints of the substitution assumptions and allows no restriction on returns to scale. Thus, the Translog production function is a more flexible functional form although it presents more parameters than the Cobb-Douglas [18]. In addition, it allows for testing of interactions among various inputs. In general, the Translog function has the following form:

$$
\begin{aligned}
\log _{\mathrm{e}} Q= & \log _{\mathrm{e}} \gamma_{0}+\sum_{i} \alpha_{i} \log _{\mathrm{e}} v_{i} \\
& +1 / 2 \sum_{i} \sum_{j} \beta_{i j} \log _{\mathrm{e}} v_{j} \log _{\mathrm{e}} v_{i}
\end{aligned}
$$

where $v_{\mathrm{i}} \ldots v_{\mathrm{n}}$ are the firm's inputs and $\beta_{i j}=\beta_{j i}$ for all $i, j$.

The relevant Translog function that applies to our production function $Q=f(K, L, T)$ can be expressed as:

$$
\begin{aligned}
\log _{\mathrm{e}} Q= & \beta_{0}+\beta_{K} \log _{\mathrm{e}} K+\beta_{L} \log _{\mathrm{e}} L+\beta_{T} \log _{\mathrm{e}} T \\
& +1 / 2 \beta_{K K}\left(\log _{\mathrm{e}} K\right)^{2}+1 / 2 \beta_{L L}\left(\log _{\mathrm{e}} L\right)^{2} \\
& +1 / 2 \beta_{T T}\left(\log _{\mathrm{e}} T\right)^{2}+\beta_{K L} \log _{\mathrm{e}} K \log _{\mathrm{e}} L \\
& +\beta_{L T} \log _{\mathrm{e}} L \log _{\mathrm{e}} T+\beta_{T K} \log _{\mathrm{e}} T \log _{\mathrm{e}} K
\end{aligned}
$$

\section{Overview on Regression Splines}

Regression equations attempt to model the relationship between target and predictor variables using a single function (e.g. linear, log linear) of the predictor variables, describing the contribution of each predictor (independent) variable with a single coefficient. If the relationship is linear or approximately linear, the regression equation can provide an accurate and useful estimate. To capture any relevant non-linearity, higher order terms $\left(x^{2}, x^{3}\right.$, etc.) may be introduced but the coefficients of these terms will be estimated over the range of the whole dataset (global nature of fit). However, this might not be the most appropriate functional form since it is based on a rigid assumption about the relationship [19]. Thus, if the functional form of the dataset varies with each sub-region, local (i.e. sub-region) features of the true function might not be captured using the regression approach.

On the other hand, an RS approach models the relationship between target and predictor variables using a piecewise polynomial function, such as piecewise continuous linear functions (linear splines) or piecewise cubic functions with continuous derivative of predictor variable [19]. A piecewise polynomial function $f(x)$ can be obtained by dividing the range of each predictor variable into one or more intervals and representing function $f$ by a separate polynomial in each interval [20]. Thus, splines are described as piecewise polynomials whose segments have been joined together smoothly at the knots [21], where a knot specifies the end of one region of data and the beginning of another [22]. An RS function can be expressed as a linear combination of piecewise polynomial basis functions (BF) that are joined together smoothly at the knots and the coefficients of the basis function are estimated by minimizing the sum of square errors. RS performs a polynomial fit in each region with constraints at the knots using the least squares criterion. Accordingly, the parameters of the regression functions change from one region to another. Since this process is same as the estimation process of regression, this estimated spline is called the Regression Spline.

MARS approach was motivated by adaptive RS [19] and the recursive partitioning regression (RPR) approach [23]. Although RPR is commonly used for multivariate function approximation, it is discontinuous at the region 
boundaries. Thus, MARS improved this disadvantage of RPR while it retained the adaptability of RPR [24]. MARS is highly adaptive and automatically selects locations and degree of knots. It builds a model in a two-phase process, using a forward stepwise regression selection and backwards-stepwise deletion strategy. In the first phase, MARS builds an overfitted model by adding basis functions. In the second phase, basis functions that have the least contribution to the model are deleted where removal causes the smallest increase in residual squared error and the model is optimized [20,22]. Therefore, the function obtained using the MARS approach can be described as the form:

$$
Y=\beta_{0}+\sum_{k=1}^{K} \beta_{k} h_{k}(\mathbf{x})
$$

where $\beta_{0}$ is the coefficient of the constant basis function, $\beta_{k}(k=1, \ldots, K)$ are the coefficients of the basis functions, $K$ is the number of basis functions in the model, $h_{k}(\mathbf{x})$ are product of spline basis functions, i.e. $h_{k}(\mathbf{x})=$ $h_{k}\left(x_{1}, \ldots, x_{q}\right)=\prod_{i j} f_{i j}\left(x_{i}\right)$ where $x_{1}, \ldots, x_{q}$ are the independent variables, $f_{i j}$ is a spline basis function for the $i$ th independent variable $x_{i}$ at $j$ th knot. MARS uses the basis functions in pairs of the form $(x-t)_{+}$and $(t-x)_{+}$where $t$ is the knot. The ' + ' represents positive part, thus, $(x-t)_{+}$means $x-t$ if $x>t$ or 0 if otherwise and $(t-x)_{+}$means $t-x$ if $x<t$ or 0 if otherwise [19,20]. MARS provides ANOVA decomposition, which identifies the relative contributions of each of the predictor variables and the interactions between variables, and handles missing values [24].

A MARS model can be generated that allows no interaction between the input variables, or to permit interactions between two or more variables. MARS models that involve interactions between variables have a hierarchical, tree-like structure, with parent and child relationships between basis functions. Modeling the translog function using MARS involves permitting two-way interactions between input variables.

\subsection{Comparison to Data Envelopment Analysis}

In the past, the Data Envelopment Analysis (DEA) approach has been used in IT productivity research [10]. While both the RS and DEA are considered to be nonparametric approaches to analyzing data, some of the differences between RS and DEA are presented to better understand the characteristics of RS approach.

First, DEA models are used to determine the technical efficiency of each object in the dataset, where the technical efficiency score is a relative value between 0 and 1. Since the technical efficiency of an object in the given dataset could change even if a single observation is added or removed from the dataset, DEA models are typically not used for predictive purposes, but they have
Table 3

Descriptive statistics of the dataset

\begin{tabular}{llccc}
\hline Name of variable & Variable & Mean & SD & $N$ \\
\hline Adjusted Patient Days & $\log _{\mathrm{e}} Q$ & 10.514 & 0.850 & 1130 \\
IT Stock & $\log _{\mathrm{e}} T$ & 15.526 & 0.904 & 1130 \\
Non-IT Capital & $\log _{\mathrm{e}} K$ & 13.266 & 1.266 & 1130 \\
Non-IT Labor & $\log _{\mathrm{e}} L$ & 16.136 & 0.965 & 1130 \\
\hline
\end{tabular}

been used in explanatory models in a two-stage process that involves regression as the second stage [10]. However, an RS model can be used for explanation and prediction. Second, using DEA, coefficients (i.e. weights) are generated for both the input production variables (e.g. Non-IT Labor, IT Stock) and the output production variables (e.g. Adjusted Patient Days, Profit), and different observations may have different sets of coefficients. On the other hand, using RS, coefficients are typically generated for the input production variables only.

\section{Empirical results and discussion}

\subsection{Description of the results}

The RS model that was generated had a R-Squared value of 0.90 , which suggests that it has relatively high predictive power. Table 3 describes descriptive statistics of the dataset, Table 4 describes the relative importance of variables in this model, and Table 5 describes the RS model in terms of basis functions and their coefficients.

As shown in Table 5, the BF8 and BF9 was created but deleted to optimize the model and the BF4 does not have a coefficient since it only exists as part of other basis functions (e.g. BF5, BF6, and BF7). From these basis functions, we can identify the knots for our predictor variables: the knots for IT Stock are represented by $T_{\mathrm{cv} 1}, T_{\mathrm{cv} 2}$, and $T_{\mathrm{cv} 3}$ where $\log _{\mathrm{e}}\left(T_{\mathrm{cv} 1}\right)=14.086, \log _{\mathrm{e}}\left(T_{\mathrm{cv} 2}\right)=15.967$, and $\log _{e}\left(T_{\mathrm{cv} 3}\right)=$ 14.738; the knots for Non-IT Labor $(L)$ are represented by $L_{\mathrm{cv} 1}$ and $L_{\mathrm{cv} 2}$, where $\log _{\mathrm{e}}\left(L_{\mathrm{cv} 1}\right)=16.703$ and $\log _{\mathrm{e}}\left(L_{\mathrm{cv} 2}\right)=$ 15.350; and the knots for Non-IT Capital $(K)$ are represented by $K_{\mathrm{cv} 1}$ and $K_{\mathrm{cv} 2}$ where $\log _{\mathrm{e}}\left(K_{\mathrm{cv} 1}\right)=12.220$ and $\log _{\mathrm{e}}\left(K_{\mathrm{cv} 2}\right)=13.714$.

Table 4

Relative importance of variables

\begin{tabular}{lllr}
\hline Name of variable & Variable & Cost of omission & Importance \\
\hline Non-IT Capital & $\log _{\mathrm{e}} K$ & 0.143 & 100.000 \\
Non-IT Labor & $\log _{\mathrm{e}} L$ & 0.139 & 97.271 \\
IT Stock & $\log _{\mathrm{e}} T$ & 0.081 & 30.360 \\
\hline
\end{tabular}


Table 5

Final model

\begin{tabular}{|c|c|c|c|c|c|}
\hline \multicolumn{2}{|l|}{ Basis function (BF) } & \multirow{2}{*}{$\begin{array}{c}\text { Coefficient } \\
11.923\end{array}$} & \multirow[t]{2}{*}{ Variable } & \multirow[t]{2}{*}{ Parent } & \multirow[t]{2}{*}{ Knot (log value) } \\
\hline 0 & & & & & \\
\hline 1 & $\mathrm{BF} 1=\max \left(0, \log _{\mathrm{e}} L-16.703\right)$ & 1.114 & $\log _{\mathrm{e}} L$ & & 16.703 \\
\hline 2 & $\mathrm{BF} 2=\max \left(0,16.703-\log _{\mathrm{e}} L\right)$ & -1.243 & $\log _{\mathrm{e}} L$ & & 16.703 \\
\hline 3 & $\mathrm{BF} 3=\max \left(0, \log _{\mathrm{e}} K-12.220\right)$ & -0.589 & $\log _{\mathrm{e}} K$ & & 12.220 \\
\hline 4 & $\mathrm{BF} 4=\max \left(0,12.220-\log _{\mathrm{e}} K\right)$ & & & & \\
\hline 5 & $\mathrm{BF} 5=\max \left(0, \log _{\mathrm{e}} L-15.350\right) * \mathrm{BF} 4$ & -1.067 & $\log _{\mathrm{e}} L$ & $\log _{\mathrm{e}} K$ & 15.350 \\
\hline 7 & $\mathrm{BF} 7=\max \left(0, \log _{\mathrm{e}} T-14.086\right)^{*} \mathrm{BF} 4$ & 0.611 & $\log _{\mathrm{e}} T$ & $\log _{\mathrm{e}} K$ & 14.086 \\
\hline 10 & $\mathrm{BF} 10=\max \left(0,15.967-\log _{\mathrm{e}} T\right)$ & -0.207 & $\log _{\mathrm{e}} T$ & & 15.967 \\
\hline 11 & $\mathrm{BF} 11=\max \left(0, \log _{\mathrm{e}} T-14.738\right)^{*} \mathrm{BF} 3$ & 0.050 & $\log _{\mathrm{e}} T$ & $\log _{\mathrm{e}} K$ & 14.738 \\
\hline 12 & $\mathrm{BF} 12=\max \left(0,14.738-\log _{\mathrm{e}} T\right) * \mathrm{BF} 3$ & 0.856 & $\log _{\mathrm{e}} T$ & $\log _{\mathrm{e}} K$ & 14.738 \\
\hline 13 & $\mathrm{BF} 13=\max \left(0, \log _{\mathrm{e}} K-13.714\right) * \mathrm{BF} 2$ & 0.597 & $\log _{\mathrm{e}} K$ & $\log _{\mathrm{e}} L$ & 13.714 \\
\hline
\end{tabular}

Given these basis functions and their coefficients described in Table 5, our Translog production function can be expressed as follows:

$$
\begin{aligned}
\log _{\mathrm{e}} Q= & 11.923+1.114 * \mathrm{BF} 1-1.243 * \mathrm{BF} 2-0.589 * \\
& \mathrm{BF} 3-1.067 * \mathrm{BF} 5+0.370 * \mathrm{BF} 6+0.611 * \\
& \mathrm{BF} 7-0.207 * \mathrm{BF} 10+0.050 * \mathrm{BF} 11+0.856 * \\
& \mathrm{BF} 12+0.597 * \mathrm{BF} 13
\end{aligned}
$$

The reader should note that if the sign of the coefficient of a basis function is the same as the sign of the variable in that function (e.g. BF1, BF10) then the contribution of given variable in terms of that basis function is positive, while if the corresponding signs are different then the contribution of given variable in terms of that basis function is negative (e.g. BF3, BF12).

\subsection{Interpretation of the results}

These results suggest the following:

(1) Investments in IT Stock (T)

- They have an impact on productivity since IT Stock $(T)$ is involved in four (4) of the basis functions (i.e. BF7, BF10, BF11, and BF12) that are in the RS model.

- The overall impact on organizational productivity is conditioned both by the amount invested in the IT Stock (see BF10) and the investments in Non-IT Capital (see $\mathrm{BF} 7, \mathrm{BF} 11$, and BF12).

- Under certain conditions, investments in IT Stock $(T)$ could have a negative impact on productivity.

For example, if the investments in Non-IT Capital $(K)$ are greater than $K_{\mathrm{cv} 1}$ and the investments in IT Stock (T) are less than $T_{\mathrm{cv} 3}$, the overall impact of IT Stock could be negative. In this case, although the contribution of the IT Stock from BF10 is positive, its contribution from $\mathrm{BF} 12$ is negative because the sign of $\log _{\mathrm{e}} T$ in BF12 is negative while the sign of the coefficient of the BF12 is positive. Thus, the overall impact could be negative. See Fig. 1.

- Under certain conditions, investments in IT Stock $(T)$ could have a positive impact on productivity.

For example, if the investments in Non-IT Capital $(K)$ are less than $K_{\mathrm{cv} 1}$, then the impact of IT Stock $(T)$ on productivity is positive as for each relevant basis functions $(\mathrm{BF})$ that involve IT Stock, the sign of variable in the $\mathrm{BF}$ and the sign of the coefficient of the $\mathrm{BF}$ are the same (i.e. BF10 and BF 7). See Fig. 2.

- The impact of investments in the IT Stock $(T)$ is not conditioned by investments of Non-IT Labor $(L)$ as none of the basis functions that involve the IT Stock (i.e. BF7, $\mathrm{BF} 10, \mathrm{BF} 11$, and BF12) has Non-IT Labor $(L)$ as a parent.

- The overall impact on organizational productivity is not uniform. There are different coefficients for each of the basis

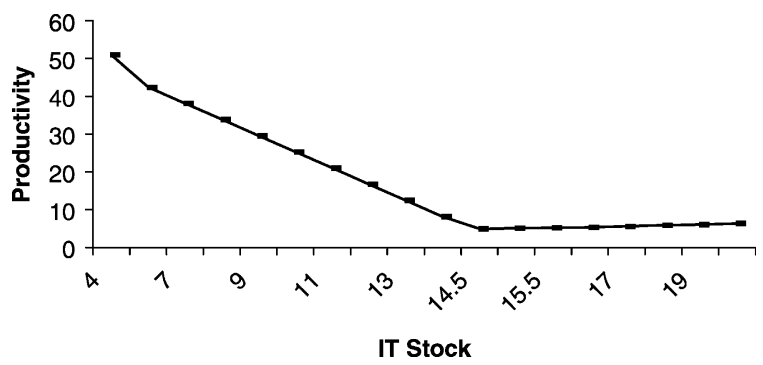

Fig. 1. The impact of investments in IT stock on productivity when Non-IT Capital is fixed at $K_{\mathrm{cv} 1+} \cdot K_{\mathrm{cv} 1+}$ means the investments in Non-IT Capital are greater than the value of knot $K_{\mathrm{cv} 1}$.

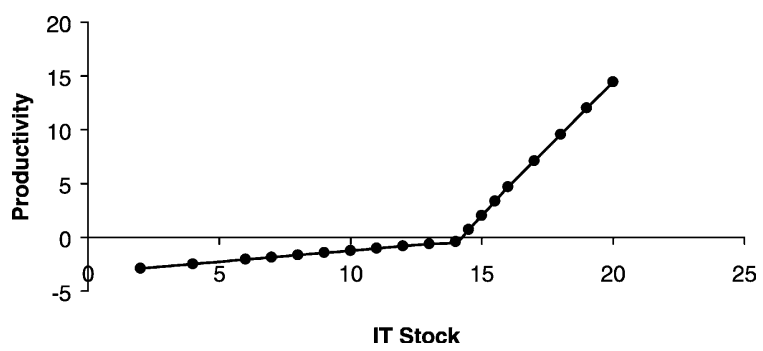

Fig. 2. The impact of investments in IT stock on productivity when Non-IT Capital is fixed at $K_{\mathrm{cv} 1-} . K_{\mathrm{cv} 1-}$ means the investments in Non-IT Capital are less than the value of knot $K_{\mathrm{cv} 1}$. 


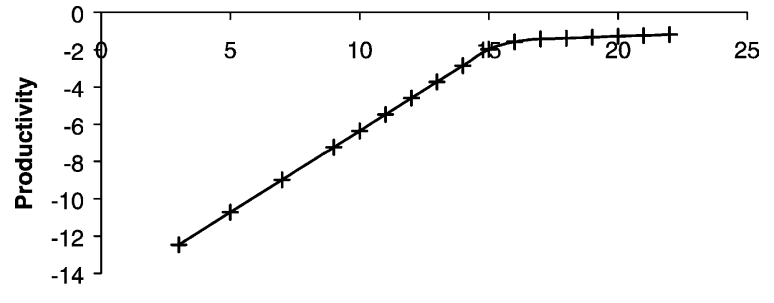

Non-IT Labor

Fig. 3. The impact of investments in Non-IT Labor on productivity when Non-IT Capital is fixed at $K_{\mathrm{cv} 1-}$.

functions that involve the IT Stock (i.e. BF7, BF10, BF11, and BF12) and the investments in Non-IT Capital $(K)$.

\section{(2) Investments in Non-IT Labor (L)}

- They have an impact on productivity since Non-IT Labor (L) involved in four (4) of the basis functions (e.g. BF1, $\mathrm{BF} 2, \mathrm{BF} 5$, and BF6) that are in the RS model.

- The overall impact of the investments is determined both by the amount invested in the Non-IT Labor (see BF1 and BF2) and the investments in Non-IT Capital (see BF5 and BF6). However, the impact of Non-IT Labor $(L)$ investments is always positive whether the investments in Non-IT Capital $(K)$ is less than $K_{\mathrm{cv} 1}$ (see Fig. 3) or greater than $K_{\mathrm{cv} 1}$ (see Fig. 4).

- The overall impact of the investments on organizational productivity is not uniform. There are different coefficients for each of the basis functions that involve the Non-IT Labor (i.e. BF1, BF2, BF5, and BF6). See Figs. 3 and 4.

\section{(3) Investments in Non-IT Capital $(K)$}

- They have an impact on productivity through interactions with other variables (IT Stock $(T)$ or Non-IT Labor $(L)$ ) since Non-IT Capital involved in seven (7) of the basis functions (two as a main variable-BF3 and BF13, five as a parent in the interactions-BF5, BF6, BF7, BF11, and BF12).

- In terms of their impact on productivity, the interaction between Non-IT Capital $(K)$ and Non-IT Labor $(L)$ is a complex one, as both variables condition each other

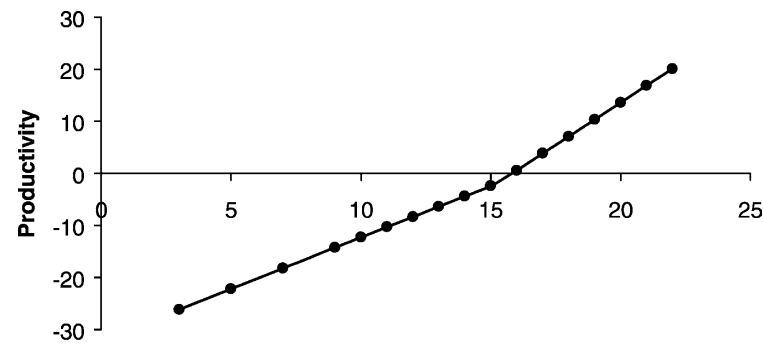

Non-IT Labor

Fig. 4. The impact of investments in Non-IT Labor on productivity when Non-IT Capital is fixed at $K_{\mathrm{cv} 1+}$.

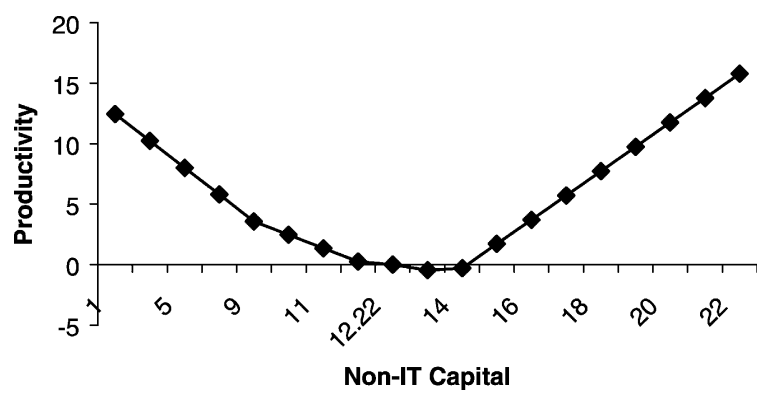

Fig. 5. The impact of investments in Non-IT Capital on productivity when Non-IT Labor is fixed at $L_{\mathrm{cv} 1-}$ and IT stock is fixed at $T_{\mathrm{cv} 1-}$. Even if IT Stock is fixed at $T_{\mathrm{cv} 1+}$, the shape of graph looks very similar.

(i.e. BF5, BF6, and BF13). Also, the overall impact of investments is determined by the amounts invested in the Non-IT Labor, Non-IT Capital, and IT Stock. Findings of our study show that investments in Non-IT Capital $(K)$ have a positive impact on productivity only under certain conditions.

For example, when the investments in Non-IT Labor $(L)$ are less than $L_{\mathrm{cv} 2}$, Non-IT Capital $(K)$ has a positive impact if the amount invested in Non-IT Capital is greater than $K_{\mathrm{cv} 1}$. In this situation, the amount invested in IT Stock does not change this impact. However, if the amount invested in Non-IT Capital is less than $K_{\mathrm{cv} 1}$, it has a negative impact (see Fig. 5).

On the other hand, if the amount invested in Non-IT Labor $(L)$ is greater than $L_{\mathrm{cv} 2}$, depending on

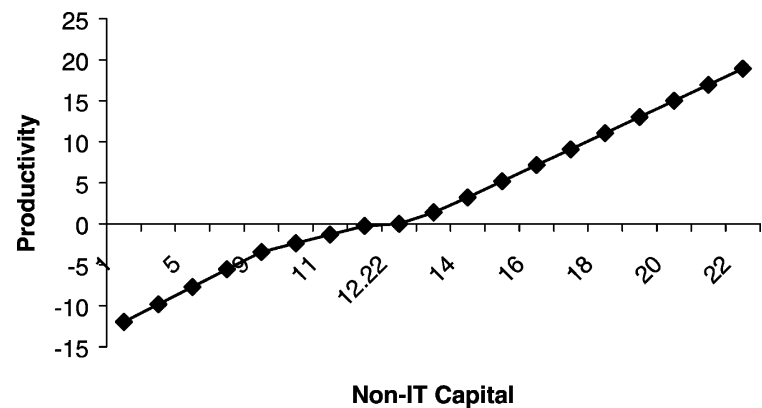

Fig. 6. The impact of investments in Non-IT Capital on productivity when Non-IT Labor is fixed at $L_{\mathrm{cv} 2+}$ and IT stock is fixed at $T_{\mathrm{cv} 1-}$.

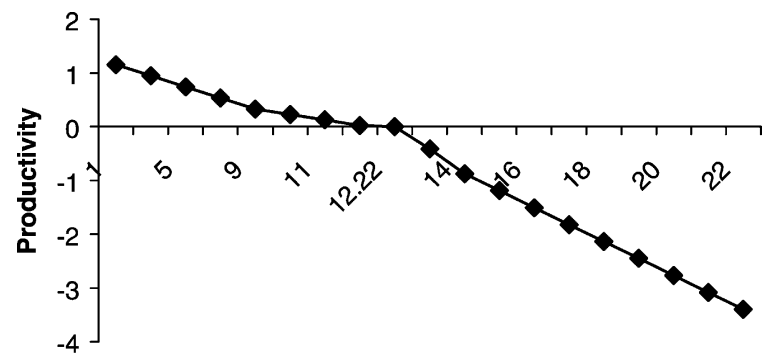

Non-IT Capital

Fig. 7. The impact of investments in Non-IT Capital on productivity when Non-IT Labor is fixed at $L_{\mathrm{cv} 2+}$ and IT stock is fixed at $T_{\mathrm{cv} 1+}$. 
the amount invested in IT Stock $(T)$, the impact of Non-IT Capital $(K)$ changes. In this situation, if the amount invested in IT Stock is less than any of its knots, the impact is positive (see Fig. 6). If the amount invested in IT Stock is greater than $T_{\mathrm{cv} 2}$, the impact is negative (see Fig. 7).

\section{Conclusion and discussion}

As investments in IT have continuously increased, numerous studies have attempted to estimate the impact of IT investments but the findings of previous studies are inconclusive. In this study, we introduced the RS approach and explored the productivity impact of IT investment in the healthcare industry. We believe that our new technique offered additional valuable insights that contribute to our understanding of complex relationship between investments in IT and organizational productivity.

Our study suggests several facts. First, each input variable has an interaction with other input variables. Thus, considering the investment amount for only one variable may not increase the overall productivity at the firm level. For example, IT Stock in our study has a positive impact on productivity only under certain conditions. When the amount invested in Non-IT Capital is less than one of its knots, $K_{\mathrm{cvl}}$, the impact of IT Stock is positive. Thus, investment decisions in one variable should not be made without considering the amount invested in all other related variables. Second, the impact of IT Stock is not uniform and it is conditioned both by the amount invested in IT Stock and the investments in Non-IT Capital. Thus, identifying an optimum level of the investment in each variable may lead to higher productivity at the firm level. Third, although the overall impact of Non-IT Labor investments is determined both by the amount invested in the Non-IT Labor and the investments in Non-IT Capital, this impact is always positive. Fourth, the overall impact of investments in Non-IT Capital is conditioned by all three categories, the amounts invested in Non-IT Capital, Non-IT Labor and IT Stock. Thus, its impact on productivity is complex.

Our findings could be valuable for the budgeting process in healthcare organizations, whether this process involves top-down budgeting, bottom-up budgeting, or a hybrid of these approaches. In top-down budgeting, top management develops and approves the enterprise-wide budget even before project and department budgets are developed. Middle and lower level managers then break down these estimates into project and department budgets. The estimates in the enterprise-wide budget are based on the top managers' judgment, experience, and past budget data. With the bottom-up approach, project and department budgets are developed before the enterprise-wide budget, and are combined into the enterprise-wide budget, which is then sent to top-management for approval. In both approaches, top-management has to make enterprise-wide budget decisions based on different scenarios in which investments amounts are aggregated at the organization level and not at the project level. In such situations 'What-If' analysis is often conducted using formal or informal models. The RS model developed in this study offers a formal approach for identifying scenarios under which additional investment in IT could have a positive impact on productivity, and scenarios under which additional investment in IT could have a negative impact on productivity.

\section{Limitations of the study and implications for future research}

While quantitative analyses based on production function are considered theoretically rigorous [25], this type of analyses cannot explain 'where' and 'how' IT contributes on organizational performance $[25,26]$. In this paper, we assume that IT investment has a direct impact on organizational performance and treats the relationship between IT investment and organizational performance as a 'black box.' Double dotted line with the arrow at the end in Fig. 8 represents this relationship.

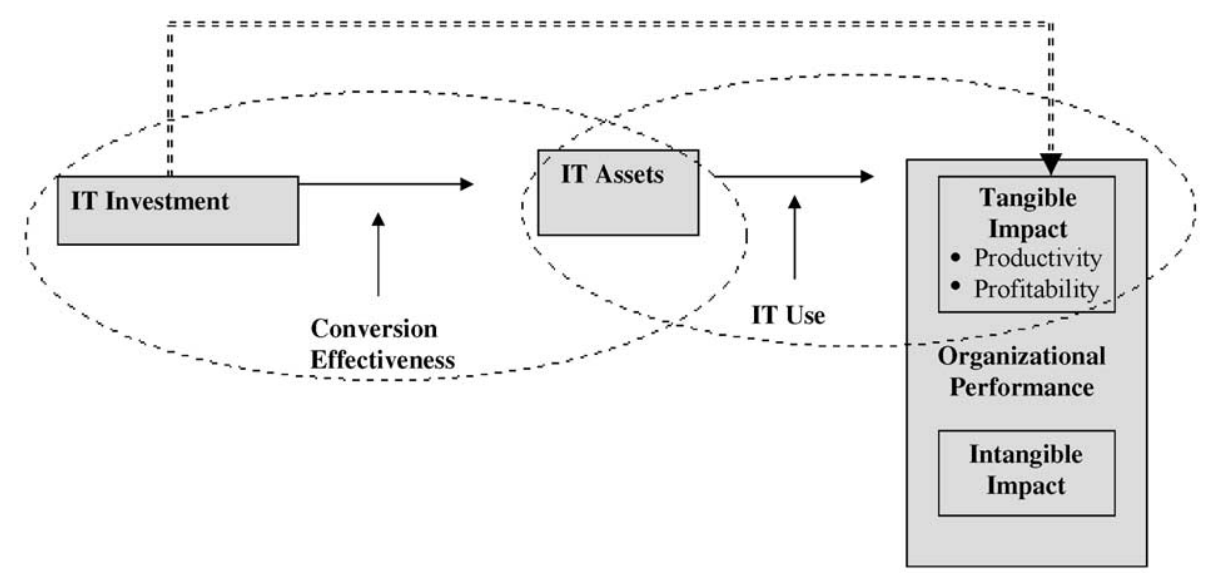

Fig. 8. A conceptual model of the impact of IT investment on organizational productivity-adapted from the models of Weill and Soh and Markus [14,30]. 
However, recent studies suggested that organizational contextual variables are important factors to consider in determining the impact of IT investment on organizational performance [27-31]. Thus, we would like to incorporate organizational contextual variables such as conversion effectiveness and IT usage that have been identified as important factors in previous studies.

Our study introduces a relatively new technique, MARS, to research on the relationship between IT and productivity. While this technique offers the opportunity for rich analysis, it also introduces concepts (e.g. basis functions, knots) with which the average reader might not be familiar. In this paper, the theoretical model is the translog production function, which limits the number of variables that can be involved in an interaction to two. It should be noted, however, that relationships involving more than two variables can be easily identified using RS analysis. While we could have presented such relationships in this study, the resulting RS model would be more complex and it is likely that the average reader would be unfamiliar with the corresponding theoretical model. We therefore decided that at this stage it would be best to strike a balance by introducing some of the advantages of RS analysis using two-way interaction.

For future research, we also intend to perform another analysis using the same dataset but include only years before Diagnostically Related Group (DRG) or only years after DRG since implementation of DRG in 1983 fundamentally changed how hospitals get reimbursed. Until 1983, hospitals were reimbursed for the service performed on patients. However, after DRGs were implemented, the hospital would be paid the same for patients in the same category. Thus, hospitals were given an incentive to keep costs down by establishing more efficient operations [32]. Since the dataset we used in this study includes the period before and after DRGs, findings from each period could be compared to investigate the difference of the IT impact in the healthcare industry.

\section{Acknowledgements}

We are grateful to Professors Byungtae Lee and Nirup Menon for sharing their dataset and Professor Menon's SAS program with us, thus facilitating this study. We also thank the anonymous referee and the editor for their valuable comments that significantly improved the quality of this paper.

\section{References}

[1] S. Dewan, C.-K. Min, The substitution of information technology for other factors of production: a firm level analysis, Management Science 43 (12) (1997) 1660-1675.

[2] B. Farbey, F. Land, D. Targett, Targett evaluating investments in IT: findings and a framework, in: L.P. Wilcocks, S. Lester (Eds.), Beyond the IT Productivity Paradox, Wiley, 1999.

[3] E. Brynjolfsson, The productivity paradox of information technology, Communications of the ACM 36 (12) (1993) 66-76.
[4] E. Brynjolfsson, L.M. Hitt, Paradox lost? Firm-level evidence on the returns to information systems spending, Management Science 42 (4) (1996) 541-558.

[5] L.M. Hitt, E. Brynjolfsson, Productivity, business profitability, and consumer surplus: three different measures of information technology value, MIS Quarterly 20 (2) (1996) 121-142.

[6] B. Prasad, P. Harker, Examining the contribution of information technology toward productivity and profitability in US retail banking, Working paper no. 97-09, Financial Institutions Center, The Wharton School, 1997.

[7] S. Sircar, J.L. Turnbow, B. Bordoloi, A framework for assessing the relationship between information technology investments and firm performance, Journal of Management Information Systems 16 (4) (2000) 69-97.

[8] R. Garretson, Greenspan hails technology spending, InfoWorld 21 (21) (1999) 32.

[9] B. Shao, W. Lin, Examining the determinants of productive efficiency with IT as a production factor, Journal of Computer Information Systems 41 (1) (2000) 25-30.

[10] B. Shao, W. Lin, Measuring the value of information technology in technical efficiency with stochastic production frontiers, Information and Software Technology (43) (2001) 447-456.

[11] S. Ward, Companies squander billions on tech, USA Today May 20 (2002).

[12] N. Menon, B. Lee, L. Eldenburg, Productivity of information systems in the healthcare industry, Information Systems Research 11 (1) (2000) 83-92.

[13] G.W. Loveman, An assessment of the productivity impact of information technologies, in: T.J. Allen, M.S. Scott Morton (Eds.), Information Technology and the Corporation of the 1990s: Research Studies, Oxford University Press, 1994, pp. 84-110.

[14] P. Weill, The relationship between investment in information technology and firm performance: a study of the valve manufacturing sector, Information Systems Research 3 (4) (1992) 307-333.

[15] B. Lee, N. Menon, Information technology value through different normative lenses, Journal of Management Information Systems 16 (4) (2000) 99-119.

[16] J. Henderson, R. Quandt, Microeconomic Theory: A Mathematical Approach, McGraw-Hill, 1980.

[17] B. Shao, Investigating the value of information technology in productive efficiency: an analytic and empirical study, $\mathrm{PhD}$ Dissertation, State University of New York, Buffalo, 2000.

[18] D. Evans, C. Green, V. Murinde, The importance of human capital and financial development in economic growth: new evidence using the translog production function, Finance and Development Research Programme Working Paper Series, Paper No. 22 November (2000) $1-31$.

[19] T.J. Hastie, R.J. Tibshirani, Generalized Additive Model, Chapman and Hall, 1990.

[20] T.J. Hastie, R.J. Tibshirani, Friedman, The Elements of Statistical Learning: Data Mining, Inference, and Prediction, Springer, New York, 2001.

[21] R. Eubank, Spline Smoothing and Nonparametric Regression, Marcel Dekker, Inc., 1988.

[22] D. Steinberg, P.L. Colla, K. Martin, MARS User Guide, Salford Systems, San Diego, CA, 1999.

[23] L. Breiman, J. Friedman, R. Olshen, S. Charles, Classification and Regression Trees, Wadsworth International Group, 1984.

[24] J.H. Friedman, Multivariate adaptive regression splines, The Annals of Statistics 19 (1) (1991) 1-141.

[25] A. Barua, T. Mukhopadhyay, Information technologies and business performance: past, present, and future, in: R. Zmud (Ed.), Framing the Domains of IT Management Projecting the Future through the Past, Pinnaflex Education Resources, Inc., 2000.

[26] J.D. McKeen, H.A. Smith, The relationship between information technology use and organizational performance, in: R. Banker, R.J. Kaufman, M.A. Mahmood (Eds.), Strategic and Economic Impacts of 
Information Technology Investment, Idea Publishing, Middletown, 1993, pp. 405-444.

[27] D. Hoogeveen, H.J. Oppelland, A socio political model of the relationship between IT investments and business performance, Proceedings of the 35th Hawaii International Conference on Systems Sciences (2002)

[28] M. Li, L.R. Ye, Information technology and firm performance: linking with environmental, strategic and managerial contexts, Information and Management (35) (1999) 43-51.

[29] T.S.H. Teo, P.K. Wong, E.H. Chia, Information Technology (IT) investment and the role of a firm: an exploratory study, International Journal of Information Management 20 (2000) 269-286.
[30] C. Soh, M.L. Markus, How IT creates business value: a process theory synthesis, Proceedings of the 16th International Conference on Information Systems, Amsterdam, The Netherlands (1995) 29-41.

[31] L. Markus, C. Soh, Banking on information technology: converting IT spending into firm performance, in: R. Banker, R. Kaufmann, M. Mahmood (Eds.), Strategic Information Technology Management: Perspectives on Organizational Growth and Competitive Advantage, Idea Group Publishing, 1993, pp. 375-404.

[32] A.T. Sumner, C.C. Moreland, The potential impact of diagnosis related group medical management on hospital utilization and profitability, Health Care Management Review 20 (2) (1995) 92-100. 